\title{
Addition of Alpha-Tocopherol to Culture Medium Improves the Quality and Cryosurvival of Nuclear-Transferred Ovine Embryos
}

\author{
Xin-Rong PENG ${ }^{1)}$, Tao LIU $^{2)}$ and Yong ZHANG ${ }^{1)}$ \\ ${ }^{1)}$ Institute of Biotechnology, Northwest A and F University, Shaanxi 712100 and ${ }^{2)}$ Xin-Yuan Institute of Medicine and \\ Biotechnology, College of Life Sciences, Zhejiang Sci-Tech University, Zhejiang 310018, China
}

\begin{abstract}
The aim of this study was to reconstruct and cryopreserve somatic cell nuclear transferred (SCNT) ovine embryos and evaluate the effect of $\alpha$-tocopherol on blastocyst development and subsequent cryosurvival of the SCNT embryos. The $\alpha$-tocopherol $(100 \mu \mathrm{g} / \mathrm{ml})$ was added into culture medium for the SCNT embryos, the yield and total cell numbers of blastocysts were determined and the apoptosis incidences of the blastocysts were evaluated using the TUNEL assay. The blastocysts from the $\alpha$-tocopherol and untreated groups were then frozen-thawed, and their cryosurvival was assessed by in vitro culture for $48 \mathrm{~h}$. The results showed that there were no significant differences in blastocyst yield ( 26.3 vs. $22.3 \%$ ) and total cell number (68.2 vs. 64.3$)$ between the $\alpha$-tocopherol and untreated groups. However, addition of $\alpha$-tocopherol to the culture medium significantly decreased the apoptotic cell number (3.4 vs. 5.5) and significantly increased the cryosurvival of SCNT blastocysts (66.8 vs. 50.7\%). In conclusion, addition of $\alpha$ tocopherol to SCNT embryo culture medium was beneficial for improving embryo quality by decreasing the apoptotic blastocyst cell number and improving the tolerance of the embryos to cryopreservation.
\end{abstract}

Key words: Alpha-tocopherol, Apoptosis, Blastocyst, Cryopreservation, Nuclear transfer, Ovine

(J. Reprod. Dev. 54: 403-407, 2008)

$S_{\text {a }}$ omatic cell nuclear transfer (SCNT) has been successfully applied for animal cloning in many species [1]. However, application of SCNT to animal production is still limited by the low development efficiency of SCNT embryos. The difficulties in cloning may be partly due to the in vitro culture system. For in vitro culture, an environment consisting of $5 \% \mathrm{CO}_{2}$ and $95 \%$ air is widely used. Under these conditions, the oxygen $\left(\mathrm{O}_{2}\right)$ concentration is about $20 \%$, while the $\mathrm{O}_{2}$ concentration under in vivo conditions is around 5-8\% [2]. A higher oxygen concentration leads to an increased level of reactive oxygen species (ROS) and subsequent high level of oxidative stress in embryos, which is responsible for poor embryo quality [3]. Overproduction of ROS can have deleterious effects on the embryo by impairing the intracellular milieu and disturbing metabolism, which results in weakened cellular growth or apoptosis leading to embryo fragmentation [4, 5]. More frequent apoptosis occurs in blastocysts cultured in vitro than in vivo [6]. Embryos from mice [7], bovine [8] and ovine [9] cultured in vitro with a low (5\%) $\mathrm{O}_{2}$ concentration have been reported to show higher developmental rates than those cultured with $20 \% \mathrm{O}_{2}$, indicating that a high $\mathrm{O}_{2}$ concentration during in vitro culture reduces developmental ability, perhaps due to increased accumulation of ROS in the cytoplasm of developing embryos [10].

Alpha-tocopherol (vitamin E) was first discovered as an antiinfertility factor in 1922 [11], and its deficiency affects embryo survival [12-14]. Wongsrikeao et al. [15] reported that supplementation of $\alpha$-tocopherol during both recipient oocyte maturation and donor cell culture enhances blastocyst formation and

Accepted for publication: May 30, 2008

Published online in J-STAGE: June 26, 2008

Correspondence: Y Zhang (e-mail: zhangyong0085@yahoo.com.cn) efficiently blocks DNA damage in transgenic SCNT bovine embryos. The blastocyst yield and number of cells in the blastocysts are improved in bovine and porcine embryos derived from in vitro fertilization and/or SCNT porcine embryos [16-19] when $\alpha$ tocopherol is added to embryo culture medium. In contrast, Dalvit et al. [20] found that the presence of $\alpha$-tocopherol or ascorbic acid in maturation medium failed to improve the percentage of blastocysts obtained in bovine embryos derived from in vitro fertilization and that the presence of the active form of $\alpha$-tocopherol during maturation impairs the acquisition of oocyte developmental competence.

To our knowledge, no research has been conducted to verify whether $\alpha$-tocopherol has an effect on the development and cryotolerance of SCNT ovine embryos. In the present study, SCNT ovine embryos were reconstructed, and the embryos were cultured at a high $\mathrm{O}_{2}$ concentration (20\%). A physiological concentration of $\alpha$-tocopherol $(100 \mu \mathrm{g} / \mathrm{ml})$ was added to the culture medium for SCNT ovine embryos, and the effect of $\alpha$-tocopherol on developmental potential into blastocysts was investigated. In addition, we examined the survival of SCNT ovine blastocysts after cryopreservation because cryopreservation is often used as a measure to check the quality of in vitro produced embryos [21] and because cryopreservation of SCNT ovine embryos is useful for further studies and embryo transfer.

\section{Materials and Methods}

Reagents

All chemicals and media were purchased from Sigma-Aldrich Chemical (St. Louis, MO, USA) unless otherwise mentioned. 


\section{Preparation of donor cells}

Ovine fibroblast cells were obtained from the ear of a 6-monthold female and were cultured in Dulbecco's modified Eagle's medium (DMEM; Gibco-Invitrogen, Carlsbad, CA, USA) supplemented with $10 \%$ (v/v) fetal bovine serum (FBS; Gibco), $25 \mathrm{mM}$ $\mathrm{NaHCO}_{3}$ and $1 \%(\mathrm{v} / \mathrm{v})$ nonessential amino acid solution (Gibco).

\section{Preparation of oocytes}

Ovine cumulus-oocyte complexes (COCs) were collected by aspiration of follicles in ovaries transported to the laboratory in normal saline at 20-25 C within $4 \mathrm{~h}$ from the time of slaughter. The COCs were cultured in TCM-199 (Gibco) supplemented with $2.2 \mathrm{~g} / \mathrm{l} \mathrm{NaHCO}, 10 \%$ (v/v) FBS, $0.22 \mathrm{~g} / \mathrm{l}$ sodium pyruvate, $5 \mu \mathrm{g} / \mathrm{ml}$ FSH, $1 \mu \mathrm{g} / \mathrm{ml}$ estradiol $-17 \beta$ and $10 \mathrm{ng} / \mathrm{ml}$ epithelial growth factor for $24 \mathrm{~h}$. Cumulus cells were then removed by repeated pipetting in $0.1 \%(\mathrm{v} / \mathrm{v})$ hyaluronidase in Hepes-buffered $\mathrm{Ca}^{2+}$-free PBS with $0.2 \mathrm{~g} / \mathrm{ml} \mathrm{BSA}$, and oocytes with a first polar body were selected. The oocytes were enucleated with a micromanipulator (Olympus, Tokyo, Japan) in PBS supplemented with $5 \mu \mathrm{g} / \mathrm{ml}$ cytochalasin B and $10 \%$ FBS as the first polar body and adjacent cytoplasm presumably containing the metaphase-II chromosomes were extruded. After staining with $5 \mu \mathrm{g} / \mathrm{ml}$ bisbenzimide (Hoechst 33342) for 5 min, oocytes still containing DNA material were excluded.

\section{Reconstruction and activation of SCNT embryos}

A donor cell was inserted into the perivitelline space of an enucleated oocyte with a micromanipulator. The couplet was fused in fusion medium (0.28 mM mannitol, $0.1 \mathrm{mM} \mathrm{MgCl}_{2}, 0.05 \mathrm{mM}$ $\mathrm{CaCl}_{2}$ ) by placing each couplet between two stainless-steel electrodes attached to micromanipulators and subjecting them to two DC electrical pulses of $1.6 \mathrm{KV} / \mathrm{cm}$ for $10 \mu \mathrm{sec}$ with an interval of $0.5 \mathrm{sec}$. The SCNT couplets were washed and cultured for $30 \mathrm{~min}$ in modified synthetic oviductal fluid (mSOF) until confirming successful fusion based on the absence of the donor cell in the perivitelline space. The SCNT embryos were cultured for $2 \mathrm{~h}$ in $\mathrm{mSOF}$, and then chemical activation was induced by incubating them in mSOF containing $5 \mu \mathrm{M}$ ionomycin for $5 \mathrm{~min}$ at $38.5 \mathrm{C}$. After washing thoroughly in ionomycin-free mSOF, the SCNT embryos were further incubated for $4 \mathrm{~h}$ in $\mathrm{mSOF}$ supplemented with $2 \mathrm{mM}$ of 6-dimethylaminopurine.

\section{In vitro culture}

Groups of 10 to 15 SCNT embryos were placed in $50 \mu \mathrm{l}$ microdrops of mSOF supplemented with or without $100 \mu \mathrm{g} / \mathrm{ml} \alpha$ tocopherol, overlaid with mineral oil and cultured for 7 days at 38.5 $\mathrm{C}$ in a humidified atmosphere of $5 \% \mathrm{CO}_{2}$ and $95 \%$ air. The culture medium was exchanged every 2 days. The stock solution of $\alpha$ tocopherol was prepared in $95 \%$ ethanol and diluted in culture medium immediately before use. Development of embryos to the 2-cell and blastocyst stages was observed at 48 and $168 \mathrm{~h}$ of culture, respestively.

\section{Detection of apoptosis by TUNEL assay}

A TUNEL assay was performed to detect the presence of apoptotic cells in blastocysts using an in situ Cell Death Detection Kit (TMR red; Roche, Mannheim, Germany). At 168 h after SCNT, the blastocysts were washed three times in PBS supplemented with $0.1 \%$ polyvinylpyrrolidone and fixed in $4 \%(\mathrm{v} / \mathrm{v})$ paraformaldehyde/PBS solution for $24 \mathrm{~h}$ at room temperature. They were then permeabilized by incubation in $0.1 \%$ Triton X-100 in $0.1 \%$ citrate solution for $1 \mathrm{~h}$ and then incubated in TUNEL reaction medium for $1 \mathrm{~h}$ at $38.5 \mathrm{C}$ in the dark. After washing, they were transferred into $2 \mu \mathrm{g} / \mathrm{ml}$ of 4', 6-diamidine-2'-penylindole dihydrochloride (DAPI; Roche)/PBS solution and mounted on slides with a ProLong Antifade Kit (Molecular Probes, Eugene, OR, USA). As positive controls for the TUNEL assay, fixed blastocysts were incubated in $50 \mathrm{U} / \mathrm{ml} \mathrm{RNase-Free} \mathrm{DNase/PBS} \mathrm{solution} \mathrm{for} 30 \mathrm{~min}$ at $38.5 \mathrm{C}$ in the dark before the assay. To determine the total cell and apoptotic cell numbers, DAPI-positive and TUNEL-positive cells in wholemounted blastocysts were counted with a fluorescence microscope (Nikon, Tokyo, Japan), respectively.

\section{Cryopreservation}

The SCNT blastocysts harvested on Day 7 were exposed to 1.5 M ethylene glycol (EG) + 20\% (v/v) FBS + 0.1 M sucrose in PBS at room temperature for $5 \mathrm{~min}$ and then loaded into $0.25 \mathrm{ml}$-plastic straws. The straws were transferred to an alcohol bath of a programmable freezer (ET-1; Fujihira, Tokyo, Japan) pre-cooled to $-6.5 \mathrm{C}$, held there for $5 \mathrm{~min}$ and then seeded by touching the straws with a forceps pre-cooled in liquid nitrogen. The straws were cooled to $-35 \mathrm{C}$ at $0.3 \mathrm{C} / \mathrm{min}$ and then plunged into liquid nitrogen. They remained frozen for 2 weeks until being thawed.

\section{Thawing and culture of blastocysts}

The straws were thawed by holding in air for $5 \mathrm{sec}$ followed by transfer into water at $30 \mathrm{C}$ for $30 \mathrm{sec}$. The recovered blastocysts were washed three times in both $0.1 \mathrm{M}$ sucrose in PBS and mSOF and then cultured in $\mathrm{mSOF}$ for $48 \mathrm{~h}$ at $38.5 \mathrm{C}$ in a humidified atmosphere of $5 \% \mathrm{CO}_{2}$ and $95 \%$ air. Blastocysts with the original volume of the blastocoel $24 \mathrm{~h}$ after culture and an enlarged blastocoel $48 \mathrm{~h}$ after culture were considered to have survived [22].

\section{Statistical analysis}

Random distributions of oocytes and embryos were created for each experimental group, and the experiments were replicated at least five times. For each replicate, the proportions of SCNT embryos reaching cleavage and developing to the blastocyst stage were transformed by an arcsine transformation. The transformed data were analyzed using one-way ANOVA and Scheffé's F-test, and cell numbers were compared using the Student's $t$-test.

\section{Results}

\section{Effect of $\alpha$-tocopherol on development and quality of SCNT} embryos

As shown in Table 1, the cleavage rate and blastocyst yield of the SCNT embryos in $\alpha$-tocopherol group (82.0 and 26.3\%, respectively) showed no significant increase compared with the untreated group (84.8 and $22.3 \%$, respectively).

As shown in Table 2 and Fig. 1, the mean total cell number of SCNT blastocysts cultured in the presence of $\alpha$-tocopherol was 68.2, which was not significantly different from the untreated value 
Table 1. Effect of $\alpha$-tocopherol addition to embryo culture medium on the developmental ability of SCNT ovine embryos

\begin{tabular}{cccc}
\hline$\alpha$-tocopherol* & No. of SCNT embryos & $\begin{array}{c}\text { No. of cleaved embryos } \\
\text { (mean } \pm \text { SE, \%) }\end{array}$ & $\begin{array}{c}\text { No. of blastocysts } \\
\text { (mean } \pm \text { SE, \%) }\end{array}$ \\
\hline+ & 429 & $82.0 \pm 2.3$ & $26.3 \pm 2.9$ \\
- & 437 & $84.8 \pm 2.3$ & $22.3 \pm 3.6$
\end{tabular}

*100 $\mu \mathrm{g} / \mathrm{ml}$. The cleaved and blastocyst rates were calculated based on the total number of ovine oocytes in each treatment.

Table 2. Effects of $\alpha$-tocopherol addition to culture medium on the total cell number and apoptosis index of SCNT ovine blastocysts

\begin{tabular}{ccccc}
\hline$\alpha$-tocopherol* & No. of blastocysts & $\begin{array}{c}\text { Total cell number } \\
\text { (means } \pm \text { SE) }\end{array}$ & $\begin{array}{c}\text { No. of apoptotic blastomeres } \\
\text { (means } \pm \text { SE) }\end{array}$ & $\begin{array}{c}\text { Apoptosis index } \\
\text { (means } \pm \text { SE) }\end{array}$ \\
\hline+ & 30 & $68.2 \pm 3.1$ & $3.4 \pm 0.5^{\mathrm{a}}$ & $0.049 \pm 0.006^{\mathrm{a}}$ \\
- & 30 & $64.3 \pm 3.8$ & $5.5 \pm 0.5^{\mathrm{b}}$ & $0.084 \pm 0.009^{\mathrm{b}}$ \\
\hline
\end{tabular}

*100 $\mu \mathrm{g} / \mathrm{ml}$. Within each column, values with different superscripts differ significantly $(\mathrm{P}<0.05)$. The apoptosis index was calculated by dividing the No. of apoptotic blastomeres by the total cell number.
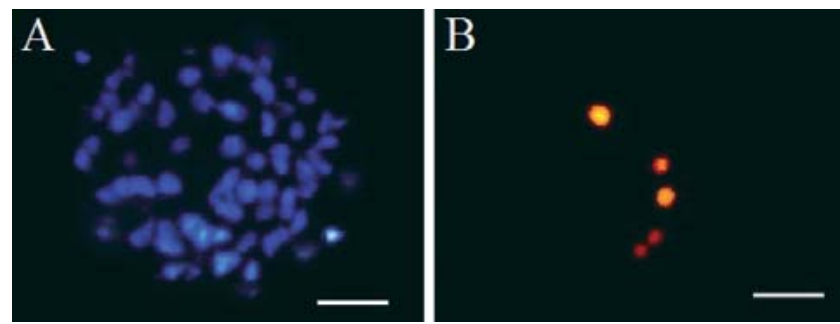

Fig. 1. Detection of apoptotic cells by TUNEL assay. A: The nuclei in the blastocysts were stained using DAPI (blue color) and visualized under a fluorescein isothiocyanate (FITC) filter set. B: Fragmented nuclei of blastocyst were stained with a TUNEL kit (red color) and visualized under an FITC filter set. Scale bars $=50 \mu \mathrm{m}$.

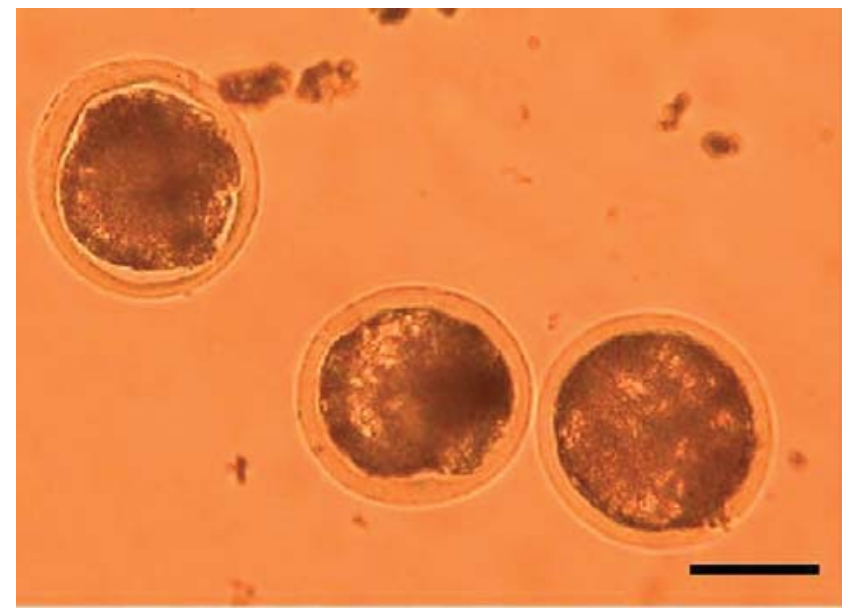

Fig. 2. SCNT ovine blastocysts surviving cryopreservation. Scale bar= $100 \mu \mathrm{m}$.

Table 3. Effect of $\alpha$-tocopherol addition to culture medium on cryosurvival of SCNT ovine blastocysts

\begin{tabular}{cccc}
\hline$\alpha$-tocopherol* & No. of thawed embryos & $\begin{array}{c}\text { Survival at 24 h } \\
\text { (mean } \pm \text { SE, \%) }\end{array}$ & $\begin{array}{c}\text { Survival at 48 h } \\
\text { (mean } \pm \text { SE, \%) }\end{array}$ \\
\hline+ & 81 & $80.5 \pm 4.0^{\mathrm{a}}$ & $66.8 \pm 3.6^{\mathrm{a}}$ \\
- & 65 & $69.2 \pm 1.7^{\mathrm{b}}$ & $50.7 \pm 4.0^{\mathrm{b}}$ \\
\hline
\end{tabular}

*100 $\mu \mathrm{g} / \mathrm{ml}$. Within each column, values with different superscripts differ significantly $(\mathrm{P}<0.05)$.

(64.3). However, the mean apoptotic cell number (3.4) and apoptosis index (0.049) in the $\alpha$-tocopherol group were significantly lower than those of the untreated group (5.5 and 0.084 , respectively).

\section{Effect of $\alpha$-tocopherol on cryosurvival of SCNT blastocysts}

As shown in Table 3 and Fig. 2, the 24 and 48 h cryosurvival rates of the SCNT blastocysts in the $\alpha$-tocopherol group were sig- nificantly higher than those of the untreated group (80.5 vs. $69.2 \%$ and 66.8 vs. 50.7\%, respectively).

\section{Discussion}

In the present study, although a slightly higher blastocyst yield (26.3 vs. 22.3\%) and total cell number (68.2 vs. 64.3) were observed in SCNT ovine embryos cultured in mSOF with $100 \mu \mathrm{g} /$ 
$\mathrm{ml} \alpha$-tocopherol compared with mSOF-alone, these differences were not statistically significant. It has been reported in SCNT porcine embryos that the yield and number are increased by addition of $\alpha$-tocopherol to culture medium [18]. This is probably due to the different methods of embryo production employed and difference in animal species. However, the blastocyst yield was not sufficient to evaluate the quality of embryos. The total cell numbers of blastocysts were determined and the apoptosis incidences of blastocysts were evaluated using the TUNEL assay. The results showed that addition of $\alpha$-tocopherol significantly decreased the number of apoptotic blastomeres, and this observation was consistent with previous reports [18, 19, 23]. Alpha-tocopherol is the most important antioxidant present in the ovary and follicular fluid. One function of $\alpha$-tocopherol is to protect embryos against ROS, which can be produced by a high concentration of $\mathrm{O}_{2}$. When ROS production overwhelms antioxidant competence, oxidative stress occurs [24]. Oxidative stress seems to damage embryos by causing peroxidation of membrane phospholipids and altering most types of cellular molecules, such as lipids, proteins and nucleic acids [25]. Moreover, blastocoele fluid possessing $\mathrm{H}_{2} \mathrm{O}_{2}$ as a cytotoxic substance [26] can induce apoptosis in inner cell mass cells. Previous studies have shown $[27,28]$ that oxidants can indirectly induce apoptosis. Our results indicated that $\alpha$-tocopherol might act as oxygen radical scavenger to protect SCNT embryos against oxidative stress and improve the quality of the resulting blastocysts.

Cryopreservation was used as another measure to check the quality of the SCNT ovine blastocysts. To the best of our knowledge, the effect of $\alpha$-tocopherol on the freezing sensitivity of SCNT ovine embryos not been previously reported. This research showed that the embryos in the $\alpha$-tocopherol group survived freezing significantly better than the untreated group. In the bovine, embryos produced in vitro were found to have higher chilling sensitivity than embryos obtained in vivo, and this phenomenon could mainly be due to suboptimal culture conditions in vitro [29, 30]. It has been suggested that the higher cryosurvival rate is attributable to the higher total cell number [21]. We speculate that the frequency of the apoptosis might also be related. In addition, $\alpha$ tocopherol protects biological membranes from lipid peroxidation and alters components of cells [31, 32]; these improve the cryotolerance of embryos. Stabilization of erythrocyte membranes can improve their survival after cryopreservation [33].

It was suggested in this paper that the high concentration of $\mathrm{O}_{2}$ had a negative effect on the development competence of SCNT ovine embryos. However, research on SCNT mouse embryos reconstructed with cumulus cells showed that a high concentration of $\mathrm{O}_{2}$ is beneficial for development of SCNT embryos [34, 35]. A higher oxygen concentration is one of the possible causes of apoptosis. Apoptotic processes have both beneficial and detrimental effects, depending on their incidence. It can remove genetically abnormal cells from early embryos; in contrast, if the ratio of apoptotic cells is elevated, the presence of massive cell death could damage embryos, although the precise threshold frequency of apoptosis that is detrimental has not yet been determined in any species [36]. We discovered in this research that $\alpha$-tocopherol improved blastocyst yield after cryopreservation and resistance to freezing in SCNT embryos probably by decreasing the number of apoptotic cells in the embryos.

In conclusion, addition of $100 \mu \mathrm{g} / \mathrm{ml} \alpha$-tocopherol to SCNT embryo culture medium was beneficial for decreasing the number of apoptotic cells in blastocysts, which might have improved tolerance of the blastocysts to cryopreservation. However, further studies are required to determine the optimum concentration of $\alpha$ tocopherol for SCNT ovine embryos.

\section{Acknowledgements}

This work was funded by a grant from the 863 Program of the Ministry of Science and Technology of China (No. 2004AA213072).

\section{References}

1. Tsunoda Y, Kato Y. Recent progress and problems in animal cloning. Differentiation 2002; 69: 158-161.

2. Fischer B, Bavister BD. Oxygen tension in the oviduct and uterus of rhesus monkeys, hamsters, and rabbits. J Reprod Fertil 1993; 99: 673-679.

3. Seino T, Saito H, Kaneko T, Takahashi T, Kawachiya S, Kurachi H. Eight-hydroxy2 -deoxyguanosine in granulosa cells is correlated with the quality of oocytes and embryos in an in vitro fertilization-embryo transfer program. Fertil Steril 2002; 77: 1184-1190.

4. Guerin P, El Mouatassim S, Menezo Y. Oxidative stress and protection against reactive oxygen species in the pre-implantation embryo and its surroundings. Hum Reprod Update 2001; 7: 175-189.

5. Harvey AJ, Kind KL, Thompson JG. REDOX regulation of early embryo development. Reproduction 2002; 123: 479-486.

6. Gjorret JO, Knijn HM, Dieleman SJ, Avery B, Larsson LI, Maddox-Hyttel P. Chronology of apoptosis in bovine embryos produced in vivo and in vitro. Biol Reprod 2003. 69: 1193-2000.

7. Goto $Y$, Noda $Y$, Narimoto K, Umaoka Y, Mori T. Oxidative stress on mouse embryo development in vitro. Free Radic Biol Med 1992; 13: 47-53.

8. Liu Z, Foote RH. Development of bovine embryos in KSOM with added superoxide dismutase and taurine and with five and twenty percent $\mathrm{O}_{2}$. Biol Reprod 1995; 53: 786790.

9. Thompson JG, Simpson AC, Pugh PA, Donnelly PE, Tervit HR. Effect of oxygen concentration on in vitro development of preimplantation sheep and cattle embryos. J Reprod Fertil 1990; 89: 573-578.

10. Kwon HC, Yang HW, Hwang KJ, Yoo JH, Kim MS, Lee CH, Ryu HS, Oh KS. Effects of low oxygen condition on the generation of reactive oxygen species and the development in mouse embryos cultured in vitro. J Obstet Gynaecol Res 1999; 25: 359-366.

11. Evans HM, Bishop KS. On the existence of a hitherto unrecognized dietary factor essential for reproduction. Science 1922; 56: 650-651.

12. Evans HM, Burr GO. General characterization of the sterility disease produced in rats by pure foods or other dietaries deficient in fat soluble vitamin E. Memoirs Univ California 1927; 8: 1-8.

13. Urner JA. The intra-uterine changes in the pregnant albino rat (Mus norvegicus) deprived of vitamin E. Anat Rec 1931; 50: 175-187.

14. Wasserman RH, Taylor AN. Metabolic role of fat-soluble vitamins D, E, and K. Annu Rev Biochem 1972; 41: 179-202.

15. Wongsrikeao $\mathbf{P}$, Nagai $T$, Agung B, Taniguchi $M$, Kunishi $M$, Suto S, Otoi $T$. Improvement of transgenic cloning efficiencies by culturing recipient oocytes and donor cells with antioxidant vitamins in cattle. Mol Reprod Dev 2007; 74: 694-702.

16. Olson SE, Seidel GE. Culture of in vitro-produced bovine embryos with vitamin E improves development in vitro and after transfer to recipients. Biol Reprod 2000; 62: 248-252.

17. Reis A, Rooke JA, McCallum GJ, Staines ME, Ewen M, Lomax MA, McEvoy TG Consequences of exposure to serum, with or without vitamin E supplementation, in terms of the fatty acid content and viability of bovine blastocysts produced in vitro. Reprod Fertil Dev 2003; 15: 275-284.

18. Jeong YW, Park SW, Hossein MS, Kim S, Kim JH, Lee SH, Kang SK, Lee BC, Hwang WS. Antiapoptotic and embryotrophic effects of alpha-tocopherol and L-ascorbic acid on porcine embryos derived from in vitro fertilization and somatic cell nuclear transfer. Theriogenology 2006; 66: 2104-2112.

19. Hossein MS, Hashem MA, Jeong YW, Lee MS, Kim S, Kim JH, Koo OJ, Park SM, Lee EG, Park SW, Kang SK, Lee BC, Hwang WS. Temporal effects of alpha-toco- 
pherol and $L$-ascorbic acid on in vitro fertilized porcine embryo development. Anim Reprod Sci 2007; 100: 107-117.

20. Dalvit G, Llanes SP, Descalzo A, Insani M, Beconi M, Cetica P. Effect of alpha-tocopherol and ascorbic acid on bovine oocyte in vitro maturation. Reprod Domest Anim 2005; 40: 93-97.

21. Amarnath D, Kato Y, Tsunoda Y. Cryopreservation of bovine somatic cell nucleartransferred blastocysts: effect of developmental stage. J Reprod Dev 2004; 50: 593-598.

22. Nguyen BX, Sotomaru Y, Tani T, Kato Y, Tsunoda Y. Efficient cryopreservation of bovine blastocysts derived from nuclear transfer with somatic cell using partial dehydration and vitrification. Theriogenology 2000; 53: 1439-1448.

23. Feugang JM, de Roover R, Moens A, Léonard S, Dessy F, Donnay I. Addition of beta-mercaptoethanol or Trolox at the morula/blastocyst stage improves the quality of bovine blastocysts and prevents induction of apoptosis and degeneration by prooxidant agents. Theriogenology 2004; 61: 71-90.

24. Matsuyama S, Reed JC. Mitochondria-dependent apoptosis and cellular $\mathrm{pH}$ regulation. Cell Death Differ 2000; 7: 1155-1165.

25. Hardy KH, Handyside AH, Winston RML. The human blastocyst: cell number, death and allocation during late preimplantation development in vitro. Development 1989; 107: 597-604.

26. Parchment RE. The implications of a unified theory of programmed cell death, polyamines, oxyradicals and histogenesis in the embryo. Int J Dev Biol 1993; 37: 75-83.

27. Jabs T. Reactive oxygen intermediates as mediators of programmed cell death in plants and animals. Biochem Pharmacol 1999; 57: 231-245.

28. Wei T, Chen C, Hou J, Xin W, Mori A. Nitric oxide induces oxidative stress and apoptosis in neuronal cells. Biochim Biophys Acta 2000; 1498: 72-79.

29. Rizos D, Lonergan P, Ward F, Duffy P, Boland MP. Consequence of bovine maturation, fertilization, or early embryo development in vitro versus in vivo: implications for blastocyst yield and blastocyst quality. Mol Reprod Dev 2002; 61: 234-248.

30. Enright BP, Lonergan P, Dinnyes A, Fair T, Ward FA, Yang X, Boland MP. Culture of in vitro produced bovine zygotes in vitro vs in vivo: implication for early embryo development and quality. Theriogenology 2000; 54: 659-673.

31. Wang X, Quinn PJ. Vitamin E and its function in membranes. Prog Lipid Res 1999; 38 309-336.

32. Atkinson J, Epand RF, Epand RM. Tocopherols and tocotrienols in membranes: a crit ical review. Free Radic Biol Med 2008; 44: 739-764.

33. Vinogradov VL, Sukhanov IUS. Stabilization of erythrocyte metabolism and membranes to improve their cryopreservation. Gematol Transfuziol 1988; 33: 44-51.

34. Wakayama T, Perry ACF, Zuccotti M, Johnson KR, Yanagimachi R. Full-term development of mice from enucleated oocytes injected with cumulus cell nuclei. Nature 1998; 394: 369-374.

35. Gao S, McGarry M, Latham KE, Wilmut I. Cloning of mice by nuclear transfer. Clon ing Stem Cells 2003; 5: 287-294.

36. Fabian D, Koppel J, Maddox-Hyttel P. Apoptotic processes during mammalian preimplantation development. Theriogenology 2005; 64: 221-231. 